Supporting Information

\title{
Recognition of Small Polar Molecules with Ionic Crystal of $\alpha$-Keggin-type Polyoxometalate with Macrocation
}

\author{
Sayaka Uchida, Ryosuke Kawamoto, and Noritaka Mizuno*
}

Department of Applied Chemistry, School of Enginnering, The University of Tokyo, 7-3-1 Hongo, Bunkyo-ku, Tokyo 113-8656 Japan 
Table S1. Lattice energies [ $\left.\mathrm{kJ} \mathrm{mol}^{-1}\right]$ needed for the expansion of $\mathbf{1 b}-\mathbf{4} \mathbf{b}^{\mathrm{a}}$

\begin{tabular}{ccccc}
\hline Substrate & $\mathbf{1 b}$ & $\mathbf{2 b}$ & $\mathbf{3 b}$ & $\mathbf{4 b}$ \\
\hline $\mathrm{CH}_{3} \mathrm{OH}$ & 18 & 37 & 67 & 104 \\
$\mathrm{C}_{2} \mathrm{H}_{5} \mathrm{OH}$ & 26 & 53 & 96 & 150 \\
$1-\mathrm{C}_{3} \mathrm{H}_{7} \mathrm{OH}$ & 33 & 67 & 122 & 190 \\
$1-\mathrm{C}_{4} \mathrm{H}_{9} \mathrm{OH}$ & 40 & 81 & 147 & 229 \\
tert $-\mathrm{C}_{4} \mathrm{H}_{9} \mathrm{OH}$ & 41 & 83 & 151 & 235
\end{tabular}

a) Lattice energies needed for the expansion from $\mathbf{1 b}-\mathbf{4 b}$ to the corresponding guest included phases $\left(1 \mathrm{~mol} \mathrm{~mol}^{-1}\right)$ were calculated by the equation of $E=$ $\mathrm{A} I /(V / 2 I)^{1 / 3}$ where $V$ and $I$ are the lattice volume $\left[\mathrm{kJ} \mathrm{mol}^{-1}\right]$ and ionic strength $(I$ $=1 / 2 \sum n_{\mathrm{i}} Z_{\mathrm{i}} ; n_{\mathrm{i}}$ is the number of ions with integer charge $Z_{\mathrm{i}}$, respectively. ${ }^{1} \quad \mathrm{~A}$ is a constant $\left(121.4 \mathrm{~kJ} \mathrm{~mol}^{-1}\right)$. The molecular volumes are calculated with the molecular weights and densities of liquids at $293 \mathrm{~K}$, assuming the cubic close-packed structures of the molecules. The molecular volumes for water, methanol, ethanol, 1-propanol, 1-butanol, and tert-butanol were 26, 57, 83, 106, 130, and $133 \AA^{3}$, respectively. (1) Glasser, L.; Jenkins, H. D. B. J. Am. Chem. Soc. 2000, 122, 632.

Table S2. Lattice energies $\left[\mathrm{kJ} \mathrm{mol}^{-1}\right]$ needed for the expansion of $\mathbf{1 b}-\mathbf{4} \mathbf{b}^{\mathrm{b}}$

\begin{tabular}{cc:ccc}
\hline Substrate & $\mathbf{1 b}$ & $\mathbf{2 b}$ & $\mathbf{3 b}$ & $\mathbf{4 b}$ \\
\hline $\mathrm{CH}_{3} \mathrm{CN}$ & 23 & 48 & 87 & 135 \\
$\mathrm{C}_{2} \mathrm{H}_{5} \mathrm{CN}$ & 31 & 62 & 114 & 177 \\
$1-\mathrm{C}_{3} \mathrm{H}_{7} \mathrm{CN}$ & 39 & 78 & 146 & 222 \\
$1-\mathrm{C}_{4} \mathrm{H}_{9} \mathrm{CN}$ & 45 & 91 & 166 & 258 \\
$1-\mathrm{C}_{5} \mathrm{H}_{11} \mathrm{CN}$ & 52 & 105 & 190 & 297
\end{tabular}

b) The calculations were carried out by the same procedure as described in Table S1. The molecular volumes for acetonitrile, propionitrile, butylonitrile, valeronitrile, and capronitrile were $75,99,126,147$, and $171 \AA^{3}$, respectively.

Table S3. Lattice energies $\left[\mathrm{kJ} \mathrm{mol}^{-1}\right]$ needed for the expansion of $\mathbf{1 b}-\mathbf{4} \mathbf{b}^{\mathrm{c}}$

\begin{tabular}{cc:c:cc}
\hline Substrate & $\mathbf{1 b}$ & $\mathbf{2 b}$ & $\mathbf{3 b}$ & $\mathbf{4 b}$ \\
\hline $\mathrm{HCOOCH}_{3}$ & 28 & 56 & 102 & 160 \\
$\mathrm{CH}_{3} \mathrm{COOCH}_{3}$ & 35 & 71 & 129 & 201 \\
$\mathrm{C}_{2} \mathrm{H}_{5} \mathrm{COOCH}_{3}$ & 42 & 84 & 153 & 239 \\
$\mathrm{CH}_{3} \mathrm{COOC}_{2} \mathrm{H}_{5}$ & 42 & 86 & 157 & 244 \\
$\mathrm{C}_{2} \mathrm{H}_{5} \mathrm{COOC}_{2} \mathrm{H}_{5}$ & 50 & 101 & 183 & 285 \\
\hline
\end{tabular}

c) The calculations were carried out by the same procedure as described in Table S1. The molecular volumes for methyl formate, methyl acetate, methyl propionate, ethyl acetate, and ethyl propionate were 89, 113, 136, 139, and 164 $\AA^{3}$, respectively. 


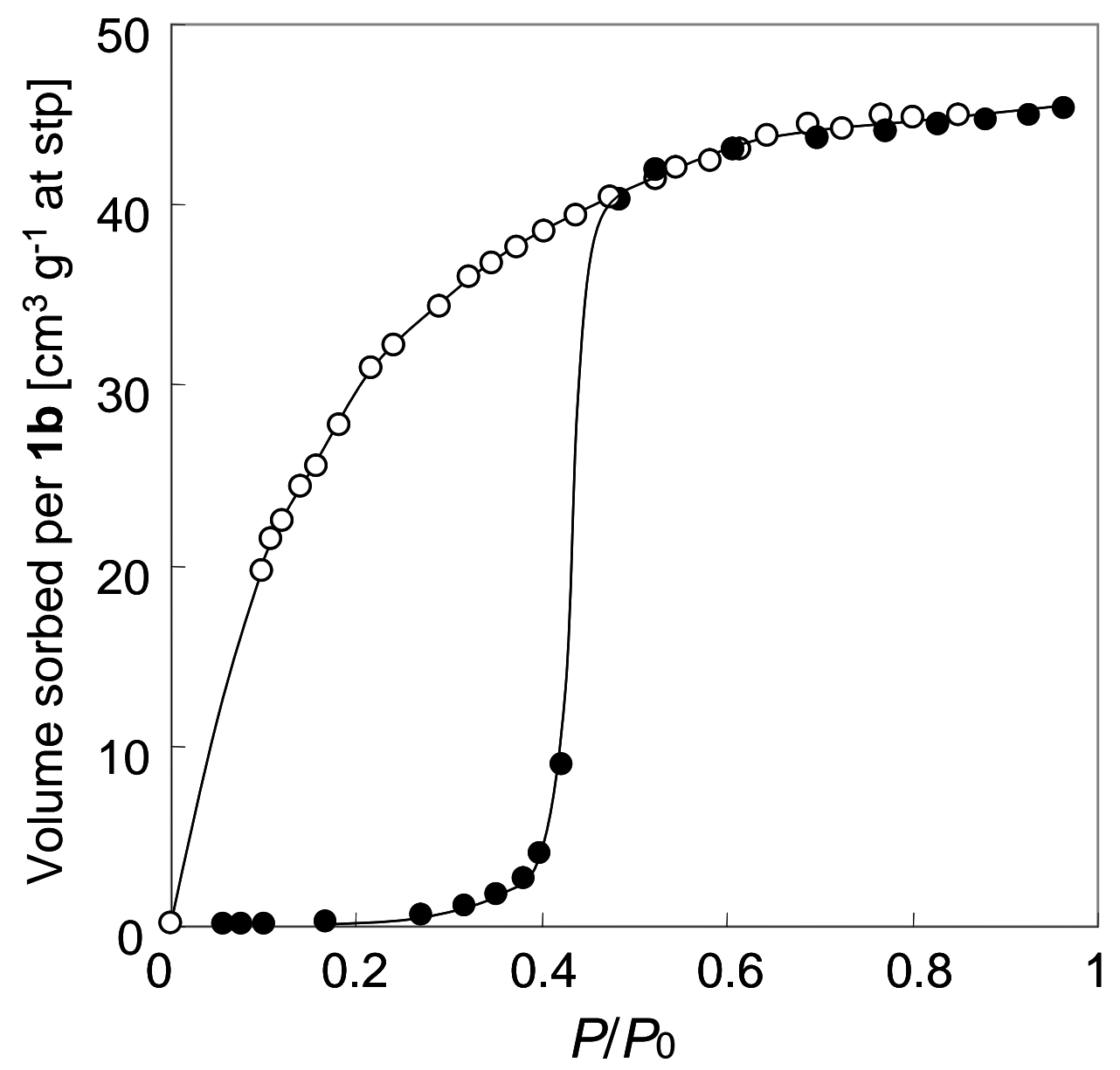

Figure S1. Ethanol sorption isotherm of $\mathbf{1 b}_{\mathbf{b}}$ at $298 \mathrm{~K}$. Closed and open circles show the sorption and destre 1 ion branch, respectively. 


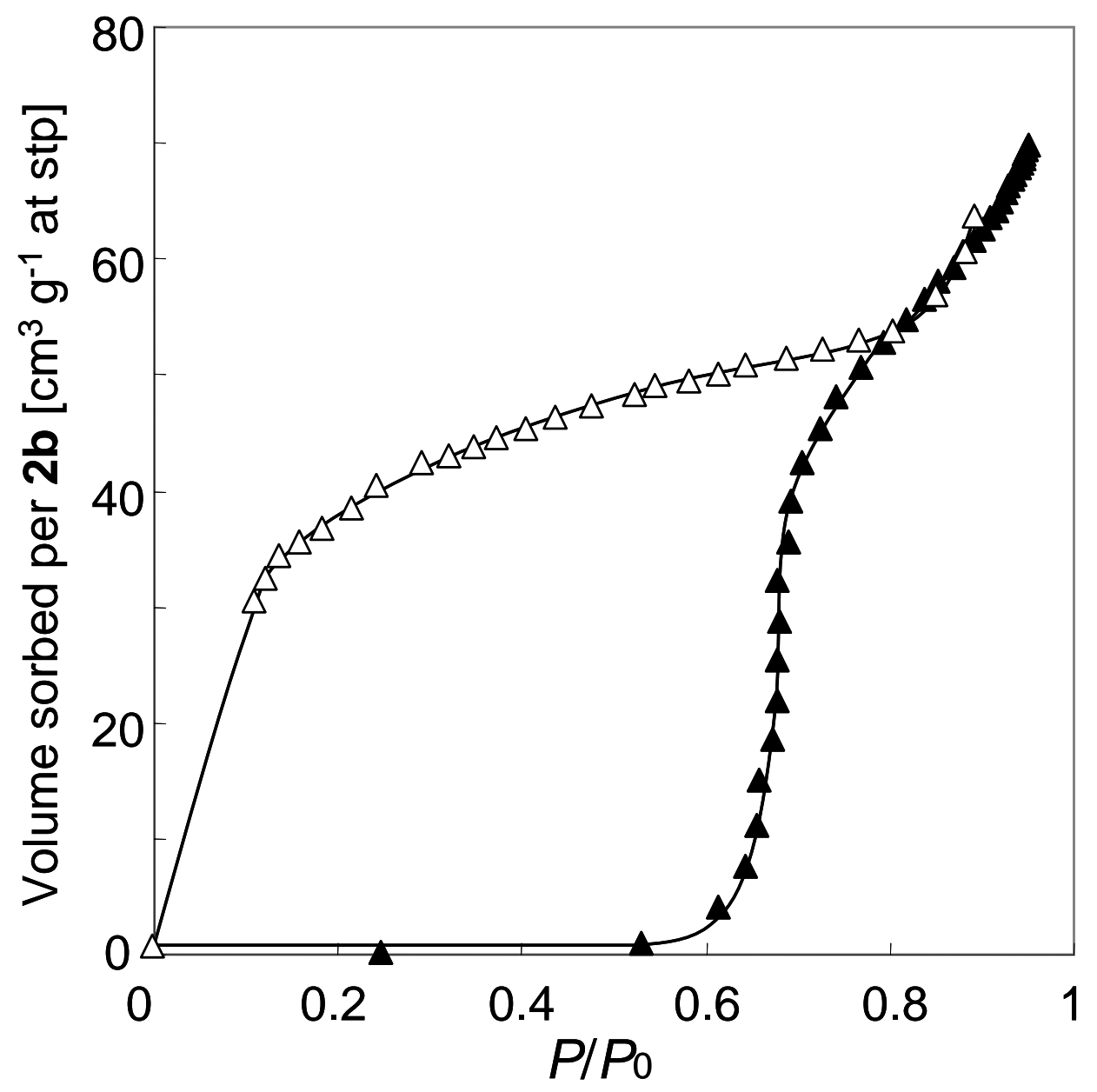

Figure S2. Ethanol sorption isftigure 2\$2t $298 \mathrm{~K}$. Closed and open triangles show the sorption and desorption branch, respectively. 